Geissler thermometers, showed for a spherical bulb an increase of 0.16 , and for a cylindrical bulb an increase of $0.2 \%$, of a degree Fahrenheit, for an additional atmosphere of pressure. Clearly, the amount of increase will depend upon the nature of the glass bulb, its thickness, size, and shape.

Many observations on vapor-pressure, on boilingpoints under increased or diminished pressure, meteorological observations at unusually high stations or in mines, are subject to this correction; and, as no general correction will be satisfactory, each thermometer will have to be separately tested.

We have written to the signal-service bureau for information on this subject, and find that they 'have the matter under consideration,' and are making ex. periments. Besides, we have been referred to papers by Loewy in Proceedings of the Royal society, 1869 , and by Marck, International bureau of weights and measures.

We write now to point out this source of error to readers of Science who may not have noticed it, and to ask if any can refer us to further memoirs and observations on the subject.

F. P. Venable.

University of North Carolina, Jan. 23.

J. W. GoRe.

\section{Is the dodo an extinct bird?}

Since the publication of an article of mine upon the origin of birds, which appeared in the Century magazine for January, 1886, there have come to me a number of interesting letters questioning the fact that the dodo is entirely extinct. From among them I select one recently received from Dr. William Barr of Bovina, Miss. My correspondent tells me that he clipped not long ago, from an English newspaper, the following item : "Mr. Manley Hopkins, consul-general of Hawaii, writes to an English journal, 'By my papers received from Hawaii, I observe that among some birds brought by the schooner Fanny from the Samoan group was a single specimen of that rara avis in terra, the dodo. I am sure your readers will be interested to hear that this bird, supposed to have become extinct more than a century ago, still lingers in the little-explored Samoan Islands of the South Pacific.'"

A number of continental naturalists, who, no doubt, have arrived at their opinions through the rumors brought home by explorers, have predicted that the dodo will some day be found to be one of the forms of the existing avifauna of the island of Madagascar.

R. W. SHUFELDT.

Fort Wingate, N. Mex., Jan. 20.

\section{Evidences of glacial action on the shores of Lake Superior.}

Evidences of glacial action are abundant about Peninsula Harbor, on the north shore of Lake Superior. The tops of the low islands, and of the hills along the shore, are rounded in a striking manner. Below the surface of the water wellpreserved grooves and scratches extend in a general north-east and south-west direction. The crevices in the granite rock which extend across the glacial markings have their northerly sides nearly intact, while the sides opposite are considerably worn. Where the crevice extends in about the same direction as the glacial mark, both of its sides are gouged out.
On Verte Island, Nipígon Bay, Lake Superior, a well-preserved beach of water-worn pebbles lies, as near as could be determined by rough measurement, two hundred and eighty feet above the present level of the bay.

A. A. Crozier.

Grand Rapids, Mich., Jan. 26.

\section{Professor Newcomb's address before the Ameri-} can society for psychical research.

In view of the utterances in the last two numbers of Science, called forth by my address before the American society for psychical research, some comment by me may not be inappropriate.

Of the two criticisms upon my address, which are put forth in the comments of Jan. 22, one seems to me well founded. It is that directed against my definition of thought-transferrence as something which is supposed to take place without any physical connection between the acting and the percipient minds. Science correctly points out that the absence of a physical medium of transfer is not implied in the doctrine of transferrence. But, while conceding this, I wish to point out that this error no more affects my conclusions than a typographical error would. The point to which my whole discourse was actually directed was that of thought-transferrence through any hitherto unrecognized channe], whether material or not. In other words, I inquired whether the observed phenomena required the admission of any new law of nature in order to explain them.

Your other criticism is in these words : "He places much emphasis, for instance, on the extreme rarity of thought-transferrence in the ordinary course of life, and implies, somewhat sarcastically, that it ought to be much more frequent."

I can find in my written paper no justification for any such remark, and cannot even guess what passage it refers to. I did, indeed, point out the wellknown and obvious fact that very rare phenomena become frequent when we learn how they are produced, or how they may be observed, and remarked, that, were thought-transferrence real, we should expect to learn how to produce it at pleasure as its conditions became better known. The great fact which I pointed out is this : after three years of painstaking labor by the English society, and one year of our own, no one shows us how to produce or observe thought-transferrence, nor indeed tells us any thing about it that we did not know before.

Professor James's remarks in Science of Feb. 5, are directed mainly to certain reflections upon the English society, for which I am not responsible to any further extent than as having made the remark which led to them. At the same time the question seems to me not devoid of interest. The ground which I take is, that the parts of the reproduced figures made by blindfolded percipients fit together in a way which could scarcely have been possible unless the percipient either saw the drawing he was making or had a knowledge of his work by some agency unknown to science. Professor James is not ready to concede this, but apparently claims that the muscular sense would have proved a sufficient guide, and suggests that I try the experiment myself. I beg leave to assure him that I did not venture on my conclusions until I had tried it. I cannot make any such drawings as those given on pp. 89 and 95 of the Proceedings of the English society by the muscular 